\title{
Costs of Musculoskeletal Injury in the California Film and Motion Picture Industry
}

\author{
Eddie Garcia ${ }^{1}$, Hamed Yazdanshenas ${ }^{2}$, Nicholas A. Kusnezov ${ }^{3}$ \& Arya Nick Shamie ${ }^{4}$ \\ ${ }^{1}$ Rutgers-New Jersey Medical School - Newark, NJ, USA \\ ${ }^{2}$ University of California, Los Angeles (UCLA) \& Charles R. Drew University of Medicine and Science, Los \\ Angeles, CA, USA \\ ${ }^{3}$ Texas Tech University Health Sciences Center - Orthopedics Texas, TX, USA \\ ${ }^{4}$ University of California, Los Angeles (UCLA), Los Angeles, CA, USA \\ Correspondence: Arya Nick Shamie, MD, Professor \& Chief, Orthopaedic Spine Surgery, UCLA School of \\ Medicine, Professor (Hon.), Zhejiang University, China. Tel: 1-310-440-2999. E-mail: Shamiemd@ucla.edu
}

Received: December 19, 2015 Accepted: March 4, 2016 Online Published: April 13, 2016

doi:10.5539/gjhs.v8n11p293

URL: http://dx.doi.org/10.5539/gjhs.v8n11p293

\begin{abstract}
Introduction: Musculoskeletal injuries may have a significant economic impact on the film and motion picture (FMP) industry. However, there is currently no comprehensive data on the cost of workers' compensation (WC) claims in the FMP industry. We present the first analysis of the cost of musculoskeletal injuries in the California (CA) FMP industry.
\end{abstract}

Methods: We reviewed the WC claims database of the Workers' Compensation Insurance Rating Bureau of California (WCIRB) from 2003 to 2007 and employment statistics through the US Bureau of Labor Statistics (BLS). We analyzed the medical cost and indemnity of musculoskeletal injuries and compared the CA FMP injury data to the data for all CA industries.

Results: From 2003-2009, the total cost of WC claims in the CA FMP industry was $\$ 19.1$ million per year, 88.6\% of which was attributed to musculoskeletal injuries. The anatomical sites which incurred the most expense were the knee, lower back, and ankle at $\$ 2.3, \$ 1.5$ and $\$ 1.1$ million per year, respectively. The most expensive causes of injury were work-directed activity and falls, totaling $\$ 5.4$ and $\$ 4.7$ million per year, respectively. The most costly types of isolated injuries were dislocations and fractures at $\$ 57,000$ and $\$ 55,000$ per claim. Additionally, the average cost per anatomic site, cause of injury and type of injury were significantly different for the CA FMP compared to CA industry in general. Over the course of the seven years that data was reviewed, orthopedic injury cost $\$ 191.71$ per worker per year while orthopedic injury cost $\$ 224.00$ per worker per year across CA industries $(\mathrm{p}<0.001)$.

Conclusion: Musculoskeletal injuries contribute substantially to both FMP expenditures and US WC costs. Though the costs for injuries were statistically significant between the FMP and CA industries, the clinical significance has yet to be seen. The data presented in this study provides detailed data to help guide future designs for reducing costs associated with workplace injury in both the FMP industry and across CA industries.

Keywords: cost, film, motion picture, industry, musculoskeletal injury

\section{Introduction}

Musculoskeletal injuries contribute substantially to both film and motion picture (FMP) expenditures and US healthcare costs and it may have a significant economic impact on the FMP industry. The California (CA) division of the United States Bureau of Labor and Statistics (US BLS) reported an increasing frequency of injuries in FMP in CA from 1980-1988 and 1.5 fatalities per 1000 injuries. This fatality rate per injury is more than three times greater than found in manufacturing and construction, which are seemingly more dangerous fields (Klowden, Chatterjee, \& Hynek, 2010; Leigh, McCurdy, \& Schenker, 2001; Rossol, 2011; Rules)

Cost is arguably one of the most influential considerations in FMP production. Injury and the resultant workers' compensation (WC) expenses may have a significant influence on this cost. Furthermore, since musculoskeletal injuries (which we define as injuries that primarily have to do with bones, muscles or their associated connective 
tissue) represent the vast majority of WC claims in the FMP industry, they also may represent a significant impact on orthopaedic and other musculoskeletal practices, particularly in areas associated with the FMP industry such as Hollywood in California or Mumbai, India (the base of Bollywood). Some studies have analyzed the cost of WC claims in industry at large (Dunning et al., 2010; Hoe, Urquhart, Kelsall, \& Sim, 2012; Leigh et al., 2001; Leigh, Yasmeen, \& Miller, 2003). However, there is presently no comprehensive data on the cost of WC claims in the FMP industry, let alone in regard to musculoskeletal injuries. As a result, the magnitudes of both influences remain unknown.

The Workers' Compensation Board of British Columbia (Work Safe BC) is one of the only sources to describe associated cost in Canadian FMP. They found that the WC cost paid by the FMP industry totaled $\$ 18.4$ million and had increased $61 \%$ from 2006-2010. A more specific cost analysis was not made public, nor is any available for the US FMP industry (Dunning et al., 2010; Leigh et al., 2001; Macfarlane, Weltz, \& Grover, 1998; Neumark, 2005).

The cost of work-related injury is an active area of study and current estimates indicate a $4.4 \%$ loss of global GDP due to such injury (Morrell et al., 1998). In a workforce comparable to that of the Unites States, the European Union self-reports that $3.2 \%$ of workers report work-related injury per year (Takala, 2014). In accordance with these values, we believe that the true magnitude of the cost of musculoskeletal injuries remains to be seen and has a substantial impact on the FMP industry and how medical professionals view the FMP industry as a patient base. In this study, we present the first analysis of the cost of musculoskeletal injuries in the CA FMP industry with detailed data to guide future designs for reducing costs associated with workplace injury.

\section{Materials and Methods}

\subsection{Data Acquisition}

This was a retrospective cross-sectional analysis of the WC claims cost database provided by the Workers' Compensation Insurance Rating Bureau of California (WCIRB). This dataset was gathered from all of the 400 licensed WC insurance companies in California across a multitude of industries and it was queried to generate two customized data sets of itemized WC claim in CA from 2003 to 2009: WC claims for all industries, and WC claims in FMP. All personal information had been removed before acquisition of the data.

Each claim included the information of total incurred medical cost, total incurred indemnity, nature of injury (e.g. amputation), part of body injured (e.g. upper arm), cause of injury (e.g. falling), and year of injury. When there was more than one claim that had identical features, the costs were added together and the claims became a single data point, albeit the data still recorded that there were multiple claims. As an illustration, three identical claims would have a cost of $\$ 150,000$, but it would be unknown how much each cost individually. This data format required the use of Pearson's chi square test instead of the student's t-test (see below).

Additional data was based on local and statewide industry employment statistics through the US Bureau of Labor Statistics (BLS). The US BLS provides local and statewide industry employment statistics per year for all industries in CA as well as for the FMP industry specifically. The industry codes for the respective FMP production sectors utilized by the WCIRB were consistent with the industry codes used by the US BLS to track employment.

\subsection{Inclusion/Exclusion Criteria}

There were 625,361 WC claims from 2003 to 2009. These were then sorted into musculoskeletal and non-musculoskeletal injuries based on the injury description codes. For example, injuries to anatomical sites associated orthopaedics (e.g. wrist, vertebrae or knee) were included. Then, injuries that were not orthopaedic in nature were excluded (e.g. syncope, poisoning or mental stress). The result was 549,705 orthopaedic claims and 75,656 non-orthopaedic claims. Similarly, there were 3,505 WC claims in the CA FMP during the same time period, 3,134 of which were orthopaedic and 371 of which were non-orthopaedic. Full injury description codes can be found in the "WCIRB Data Reporting Handbook, 2013 - Appendix 5 - Injury Description Codes," available through WCIRB.

The study combined the seventy WCIRB codes for cause of injury into the following 12 categories: explosions, criminal, work-directed activity exposure, falling, other workers, tool or machinery-related, non-tool or machinery-related, vehicular, animal-related, and other (which included rare events such as plane crashes and natural disasters). "Work-directed activity" injuries were defined as "an injury caused by a seemingly benign activity mentioned in a description of work responsibilities and were not otherwise placed in other categories." 


\subsection{Analysis}

The cost of musculoskeletal injuries was analyzed based on the type of injury, body part affected and the cause of injury. Additionally, the cost of musculoskeletal injuries from the CA FMP industry was compared to the cost data available across all CA industries. We used the CA across-industry claims to establish expected values for the CA FMP. We did this with the rationale that the across-industry data set is large (approximately 550,000 claims) and represents many, varied workplaces in CA. We then used Pearson's chi squared test to compare the percent of total cost by cause of injury, nature of injury and location of injury between the CA FMP industry and the expected value established by the across-industry data. Categories that did not have an expected percent of total cost of at least 5\% were not included due to the limitations of using Pearson's chi-squared test in data with low frequencies.

Both the cost and weighted cost per worker per year was compared between the CA FMP industry and across CA industries using the student's t-test. As per convention, statistical significance was defined as having a p-value less than 0.05 .

\section{Results}

\subsection{Cost of Musculoskeletal Injuries}

The total cost of WC claims across all CA industries from 2003 to 2009 was \$24 billion with an average cost of $\$ 3.4$ billion per year and $\$ 38,300$ per claim. Musculoskeletal injuries constituted $87.7 \%$ of this cost totaling $\$ 21$ billion, with an average of $\$ 3$ billion per year and $\$ 38,200$ per claim. The total cost of WC claims in the CA FMP industry was $\$ 134$ million during the same time period, with an average of $\$ 19.1$ million per year and $\$ 38,200$ per claim. Musculoskeletal injuries constituted $88.6 \%$ of this cost totaling $\$ 118$ million, with an average of $\$ 16.9$ million per year and $\$ 37,800$ per claim.

\subsection{Trends in Cost}

In the CA FMP industry, the average cost per worker was $\$ 244$ in 2003 which decreased until it reached $\$ 154$ in 2006 (see Figure 1). The average claim then inversely mirrored the change in FMP employment. Across CA industries, the average cost per claim had a similar trend to the FMP industry, decreasing from 2003 to 2005 and then remaining relatively stable until 2009. Notably, the average yearly expenditure for WC in the CA FMP industry was $\$ 219$ per employee per year, compared to $\$ 224$ across CA industries $(p=0.72)$, if all years are weighted equally. However, due to the sharp increase in employment in the CA FMP from 2003 to 2004 (51,000 to 81,000 employees, gradually reaching 102,000 in 2009), while employment across CA industries remained approximately the same, the weighted WC cost in the FMP industry was $\$ 191$ per worker per year compared to $\$ 224$ per worker per year $(\mathrm{p}<0.001)$.

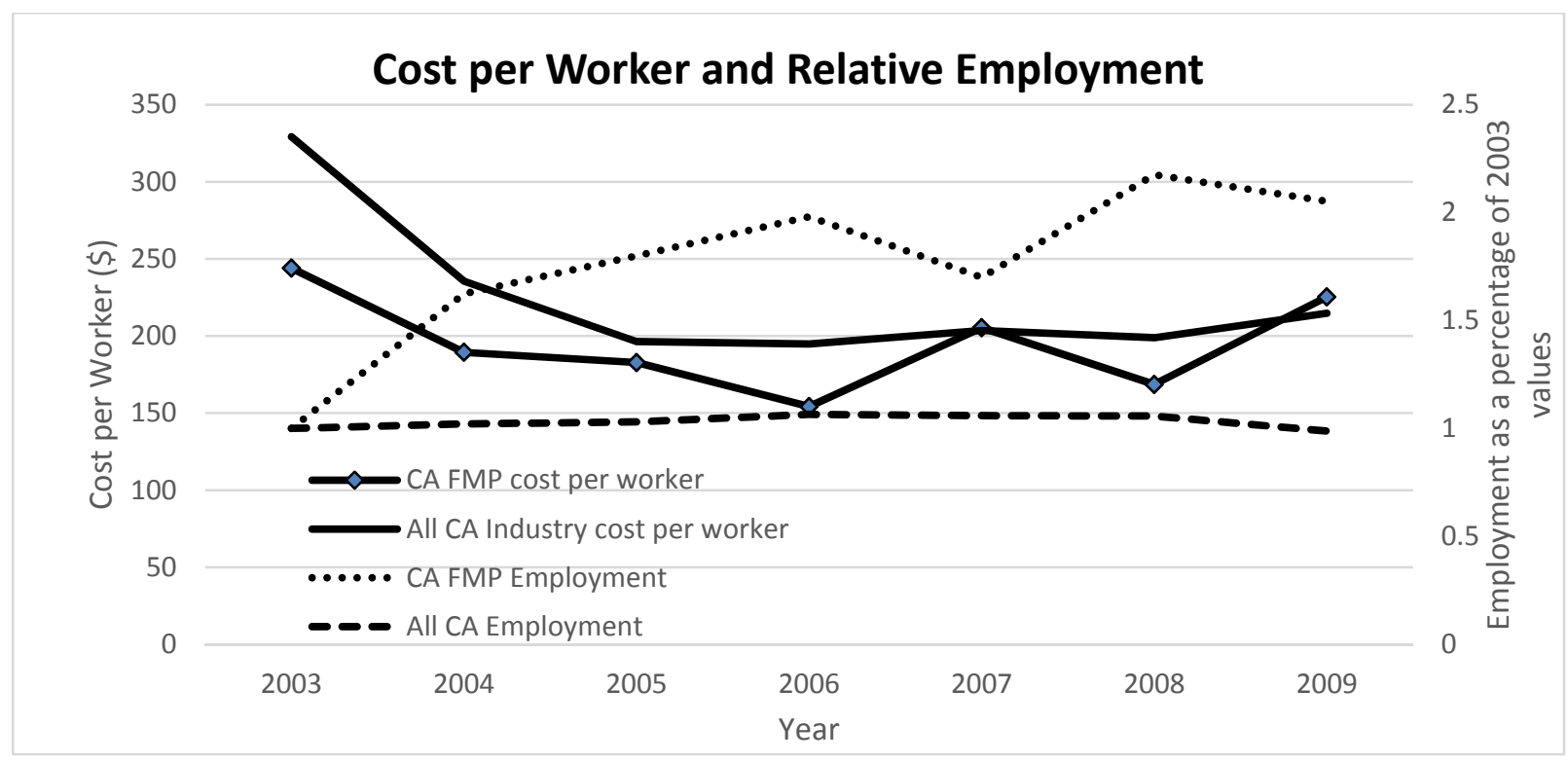

Figure 1. Cost per worker and relative employment in the CA FMP and all CA industries 


\subsection{Most Expensive Injuries by Body Part}

The most expensive anatomical sites for WC were the knee, lower back, ankle and shoulder, totaling $\$ 2.3, \$ 1.5$, $\$ 1.1$ and 1.0 million, respectively (see Table 1). The most expensive isolated anatomic sites to injure per claim were the cervical discs, cervical spinal cord, the lower leg and cervical vertebrae with an average of $\$ 84,600$, $\$ 83,200, \$ 58,900$ and $\$ 55,000$ per claim, respectively. In comparison, the data across CA industries showed that the most expensive isolated anatomical sites were the lower back, knee and shoulder, totaling $\$ 483, \$ 298, \$ 215$ and $\$ 172$ million per year. The most expensive isolated anatomical sites per claim were cervical spinal cord, thoracic/lumbar spinal cord, cervical vertebrae and thoracolumbar discs costing $\$ 201,000, \$ 113,000, \$ 100,000$, $\$ 75,700$, and $\$ 63,700$ per claim, respectively. All body parts (shoulder, wrist, finger(s), lower back, knee and multiple body regions) included in the comparative analysis of percent of total cost were significantly different between the CA FMP and across CA industries $(\mathrm{p}<0.01)$.

Table 1. Cost of Musculoskeletal Injury by Body Part, 2003-2009

\begin{tabular}{|c|c|c|c|c|c|c|c|c|}
\hline \multirow[b]{3}{*}{ Location of Injury } & \multicolumn{8}{|l|}{ Cost } \\
\hline & \multicolumn{4}{|l|}{ CA FMP } & \multicolumn{4}{|c|}{ CA All Industries } \\
\hline & $\begin{array}{l}\text { Total cost } \\
\text { per year } \\
(\$)\end{array}$ & $\begin{array}{l}\% \text { of } \\
\text { total } \\
\text { cost }\end{array}$ & $\begin{array}{l}\% \quad \text { of } \\
\text { total } \\
\text { claims }\end{array}$ & $\begin{array}{l}\text { Average } \\
\text { cost per } \\
\text { claim }(\$)\end{array}$ & $\begin{array}{l}\text { Total cost per } \\
\text { year }(\$)\end{array}$ & $\begin{array}{l}\% \text { of } \\
\text { total } \\
\text { cost }\end{array}$ & $\begin{array}{l}\% \text { of } \\
\text { total } \\
\text { claims }\end{array}$ & $\begin{array}{l}\text { Average } \\
\text { cost per } \\
\text { claim (\$) }\end{array}$ \\
\hline \multicolumn{9}{|l|}{ Neck } \\
\hline Disc & 169,249 & 1.00 & 0.4 & 84,625 & $18,363,510$ & 0.61 & 0.5 & 45,486 \\
\hline Soft tissue & 239,243 & 1.41 & 1.2 & 42,941 & $28,297,818$ & 0.94 & 1.0 & 35,970 \\
\hline Spinal cord & 11,887 & 0.07 & 0.0 & 83,210 & $16,816,975$ & 0.56 & 0.1 & 200,543 \\
\hline Vertebrae & 23,567 & 0.14 & 0.1 & 54,989 & $10,275,971$ & 0.34 & 0.2 & 75,718 \\
\hline Multiple areas & 62,191 & 0.37 & 0.2 & 62,191 & $35,129,037$ & 1.17 & 0.8 & 52,894 \\
\hline Total neck & 506,138 & 2.99 & 2.0 & 55,359 & $108,883,311$ & 3.63 & 2.6 & 52,496 \\
\hline \multicolumn{9}{|l|}{ Upper extremities (UE) } \\
\hline Shoulder* & 898,530 & 5.30 & 4.4 & 45,578 & $214,597,364$ & 7.15 & 6.6 & 41,261 \\
\hline Upper Arm & 765,724 & 4.52 & 3.6 & 47,858 & $69,248,765$ & 2.31 & 2.2 & 39,384 \\
\hline Elbow & 398,697 & 2.35 & 2.2 & 39,870 & $53,429,339$ & 1.78 & 2.1 & 32,317 \\
\hline Lower Arm & 302,138 & 1.78 & 1.9 & 36,465 & $53,428,823$ & 1.78 & 1.9 & 36,034 \\
\hline Wrist* & 651,731 & 3.85 & 3.2 & 46,082 & $171,832,378$ & 5.72 & 7.0 & 31,183 \\
\hline Hand & 535,256 & 3.16 & 3.0 & 39,859 & $101,618,759$ & 3.38 & 4.2 & 30,636 \\
\hline Wrist(s) \& hand(s) & 29,714 & 0.18 & 0.2 & 29,714 & $36,020,509$ & 1.20 & 1.3 & 34,259 \\
\hline Finger(s)* & 526,939 & 3.11 & 3.8 & 30,996 & $113,302,394$ & 3.77 & 5.7 & 25,270 \\
\hline Thumb & 149,658 & 0.88 & 1.3 & 26,190 & $27,795,500$ & 0.93 & 1.5 & 24,143 \\
\hline Multiple areas & 610,139 & 3.60 & 3.1 & 44,031 & $93,543,113$ & 3.12 & 3.4 & 34,660 \\
\hline Total UE & $4,868,526$ & 28.73 & 26.6 & 40,863 & $934,816,945$ & 31.14 & 36.0 & 33,023 \\
\hline \multicolumn{9}{|l|}{ Trunk } \\
\hline Upper back area & 207,044 & 1.22 & 0.9 & 49,976 & $41,696,427$ & 1.39 & 1.4 & 36,751 \\
\hline Lower back area* & $1,503,241$ & 8.87 & 12.1 & 27,764 & $483,318,092$ & 16.10 & 16.0 & 38,512 \\
\hline Lumbar/Sacral Vertebrae & 68,274 & 0.40 & 0.4 & 39,826 & $33,510,952$ & 1.12 & 1.0 & 41,971 \\
\hline Disc & 33,065 & 0.20 & 0.2 & 38,576 & $18,221,590$ & 0.61 & 0.4 & 63,744 \\
\hline Spinal Cord & 11,591 & 0.07 & 0.2 & 16,227 & $14,594,588$ & 0.49 & 0.2 & 113,011 \\
\hline Pelvis & 48,351 & 0.29 & 0.3 & 42,307 & $9,281,236$ & 0.31 & 0.2 & 56,741 \\
\hline
\end{tabular}




\begin{tabular}{lllllllll}
\hline Sacrum and coccyx & 9,491 & 0.06 & 0.1 & 16,609 & $3,132,897$ & 0.10 & 0.1 & 35,314 \\
Buttocks & 873 & 0.01 & 0.0 & 6,109 & $2,853,770$ & 0.10 & 0.1 & 34,621 \\
Multiple areas & 141,236 & 0.83 & 0.9 & 34,091 & $98,205,604$ & 3.27 & 2.8 & 44,440 \\
Total trunk & $2,023,166$ & 11.94 & 15.1 & 29,941 & $704,815,157$ & 23.48 & 22.2 & 40,408 \\
\hline Lower extremity (LE) & & & & & & & \\
Hip & 157,607 & 0.93 & 0.7 & 47,967 & $35,258,614$ & 1.17 & 0.8 & 53,284 \\
Upper leg & 53,637 & 0.32 & 0.4 & 31,288 & $16,059,536$ & 0.53 & 0.4 & 46,300 \\
Knee* & $2,313,160$ & 13.65 & 15.3 & 33,875 & $297,710,402$ & 9.92 & 9.9 & 38,329 \\
Lower leg & 580,820 & 3.43 & 2.2 & 58,924 & $67,820,427$ & 2.26 & 1.7 & 49,427 \\
Ankle & $1,131,465$ & 6.68 & 7.0 & 36,166 & $97,403,925$ & 3.24 & 3.5 & 35,046 \\
Foot & 795,125 & 4.69 & 3.6 & 48,823 & $68,393,842$ & 2.28 & 2.6 & 33,127 \\
Toe & 101,043 & 0.60 & 0.7 & 32,150 & $8,802,690$ & 0.29 & 0.4 & 27,014 \\
Great toe & 18,929 & 0.11 & 0.2 & 26,501 & $1,793,400$ & 0.06 & 0.1 & 20,682 \\
Multiple & 508,074 & 3.00 & 1.5 & 74,094 & $30,411,453$ & 1.01 & 0.8 & 47,935 \\
Total LE & $5,659,860$ & 33.40 & 31.6 & 40,019 & $623,654,290$ & 20.77 & 20.4 \\
\hline Multiple body regions & & & & & & 38,884 \\
Multiple regions* & $3,886,157$ & 22.94 & 24.7 & 35,192 & $630,157,351$ & 20.99 & 18.7 & 42,967 \\
\hline Total & $16,943,846$ & 100 & 100 & & $3,002,327,054$ & 100 & 100 \\
\hline Dentes & & & & & \\
\hline
\end{tabular}

* Denotes statistical significance for $\%$ of total cost, $\mathrm{p}<0.01$.

\subsection{Cost by Type of Injury}

The most costly types of injury in the CA FMP industry were strains, fractures, sprains and contusions at $\$ 5.8$, $\$ 2.9, \$ 2.1$ and $\$ 1.5$ million per year respectively (see Table 2). Across CA industries, the same injuries were the most costly and cost $\$ 1,007, \$ 335, \$ 302$ and $\$ 168$ million per year, respectively. The most costly types of isolated injuries per claim in the CA FMP industry were dislocations, fractures and ruptures at $\$ 57,00, \$ 55,000$ and $\$ 53,000$ per claim, respectively. The most costly injury classification, however, was "multiple sustained" at $\$ 98,000$ per claim. Across CA industries, the most costly injuries per claim were severances, concussions and ruptures at $\$ 89,000, \$ 81,000$ and $\$ 58,000$ per claim, respectively. Multiple injuries sustained were less than the CA FMP at only $\$ 53,000$ per claim. Lacerations were the least costly per claim at only $\$ 27,000$. All types of injury (contusion, fracture, sprain, strain, not otherwise classified) included in the comparative analysis of percent of total cost were significantly different between the CA FMP and across CA industries $(p<0.05)$.

Table 2. Cost of Musculoskeletal Injury by Type, 2003-2009

\begin{tabular}{|c|c|c|c|c|c|c|c|c|}
\hline \multirow[b]{3}{*}{ Type of Injury } & \multicolumn{8}{|l|}{ Cost } \\
\hline & \multicolumn{4}{|l|}{ CA FMP } & \multicolumn{4}{|c|}{ CA All Industries } \\
\hline & $\begin{array}{l}\text { Total cost } \\
\text { per year } \\
(\$)\end{array}$ & $\begin{array}{l}\% \text { of } \\
\text { total } \\
\text { cost }\end{array}$ & $\begin{array}{l}\text { \% of } \\
\text { total } \\
\text { claims }\end{array}$ & $\begin{array}{l}\text { Average } \\
\text { cost per } \\
\text { claim }(\$)\end{array}$ & $\begin{array}{l}\text { Total cost per } \\
\text { year }(\$)\end{array}$ & $\begin{array}{l}\% \text { of } \\
\text { total } \\
\text { cost }\end{array}$ & $\begin{array}{l}\% \text { of } \\
\text { total } \\
\text { claims }\end{array}$ & $\begin{array}{l}\text { Average } \\
\text { cost per } \\
\text { claim }(\$)\end{array}$ \\
\hline Amputation & 71,935 & 0.42 & 0.4 & 38,734 & $34,770,176$ & 1.16 & 0.8 & 56,987 \\
\hline Carpal Tunnel & 7,229 & 0.04 & 0.0 & 50,604 & $56,215,614$ & 1.87 & 2.0 & 36,487 \\
\hline Concussion & 14,683 & 0.09 & 0.1 & 34,260 & $3,658,244$ & 0.12 & 0.1 & 81,037 \\
\hline Contusion* & $1,476,642$ & 8.71 & 8.9 & 37,048 & $167,979,532$ & 5.59 & 6.3 & 33,920 \\
\hline Crushing & 172,047 & 1.02 & 1.3 & 30,108 & $36,829,044$ & 1.23 & 1.1 & 43,416 \\
\hline Dislocation & 484,891 & 2.86 & 1.9 & 56,571 & $61,171,382$ & 2.04 & 1.5 & 53,239 \\
\hline
\end{tabular}




\begin{tabular}{lllllllll}
\hline Fracture* & $2,861,920$ & 16.89 & 11.6 & 54,886 & $334,976,156$ & 11.16 & 8.4 & 50,863 \\
Inflammation & 288,559 & 1.70 & 1.8 & 35,437 & $81,016,584$ & 2.70 & 2.9 & 35,016 \\
Laceration & 588,892 & 3.48 & 3.5 & 37,819 & $97,439,674$ & 3.25 & 4.5 & 27,419 \\
Puncture & 153,391 & 0.91 & 0.8 & 41,298 & $15,236,898$ & 0.51 & 0.7 & 28,457 \\
Rupture & 135,004 & 0.80 & 0.6 & 52,502 & $17,355,407$ & 0.58 & 0.4 & 57,550 \\
Severance & 24,965 & 0.15 & 0.2 & 34,951 & $9,970,293$ & 0.33 & 0.1 & 89,477 \\
Sprain* & $2,067,402$ & 12.20 & 12.8 & 36,180 & $301,684,642$ & 10.05 & 11.1 & 34,582 \\
Strain* & $5,773,027$ & 34.07 & 39.6 & 32,537 & $1,007,147,741$ & 33.55 & 35.3 & 36,308 \\
Multiple & 432,910 & 2.55 & 1.0 & 97,754 & $126,418,809$ & 4.21 & 3.2 & 50,905 \\
Not otherwise classified* * & $2,390,348$ & 14.11 & 15.5 & 34,500 & $650,456,860$ & 21.67 & 21.7 & 38,182 \\
Total & $16,943,846$ & 100 & 100 & & $3,002,327,054$ & 100 & 100 & \\
\hline
\end{tabular}

* Denotes statistical significance for $\%$ of total cost, $\mathrm{p}<0.05$.

\subsection{Cost by Causes of Injury}

The most expensive causes of injury in the CA FMP industry were work-directed activity, falls, and non-tool or machinery related injuries totaling $\$ 5.4, \$ 4.7$ and $\$ 2.3$ million per year (Table 3). Per injury, however, the most costly causes of injury were explosions, vehicular and other workers at $\$ 298,000, \$ 54,000$ and $\$ 47,000$ per claim, respectively. The least expensive per claim were animal-related and work-directed activity at $\$ 29,000$ and $\$ 32,000$ per claim. Across CA industries, the leading causes of cost were identical to the CA FMP with work-directed activity at $\$ 1.1$ billion, falls at $\$ 776$ million and non-tool or machinery related at $\$ 279$ million per year. Per injury, the most costly were explosions, vehicular and criminal at $\$ 116,000, \$ 63,000$ and $\$ 61,000$ per injury, respectively. All causes of injury (falling, non-tool/machinery, vehicular, work-direct and not otherwise classified) included in the comparative analysis of percent of total cost were significantly different between the CA FMP and across CA industries ( $<00.05)$.

Table 3. Cost of Musculoskeletal Injury by Cause, 2003-2009

\begin{tabular}{|c|c|c|c|c|c|c|c|c|}
\hline \multirow[b]{3}{*}{ Cause of Injury } & \multicolumn{8}{|l|}{ Cost } \\
\hline & \multicolumn{4}{|l|}{ CA FMP } & \multicolumn{4}{|c|}{ CA All Industries } \\
\hline & $\begin{array}{l}\text { Total cost } \\
\text { per year } \\
(\$)\end{array}$ & $\begin{array}{l}\% \text { of } \\
\text { total } \\
\text { cost }\end{array}$ & $\begin{array}{l}\% \text { of } \\
\text { total } \\
\text { claims }\end{array}$ & $\begin{array}{l}\text { Average } \\
\text { cost per } \\
\text { claim }(\$)\end{array}$ & $\begin{array}{l}\text { Total cost per } \\
\text { year }(\$)\end{array}$ & $\begin{array}{l}\% \text { of } \\
\text { total } \\
\text { cost }\end{array}$ & $\begin{array}{l}\% \text { of } \\
\text { total } \\
\text { claims }\end{array}$ & $\begin{array}{l}\text { Average } \\
\text { cost per } \\
\text { claim }(\$)\end{array}$ \\
\hline Animals & 29,202 & 0.17 & 0.2 & 29,202 & $10,396,146$ & 0.35 & 0.4 & 32,101 \\
\hline Criminals & 0 & 0.00 & 0.0 & 0 & $16,498,057$ & 0.55 & 0.3 & 61,169 \\
\hline Explosions & 255,721 & 1.51 & 0.2 & 298,341 & $9,042,712$ & 0.30 & 0.1 & 115,299 \\
\hline Exposure & 178,592 & 1.05 & 1.0 & 40,327 & $13,110,038$ & 0.44 & 0.4 & 41,264 \\
\hline Falling* & $4,679,730$ & 27.62 & 25.8 & 40,492 & $775,992,891$ & 25.85 & 22.5 & 43,978 \\
\hline Non-Tools/Machinery* & $2,340,600$ & 13.81 & 12.5 & 41,796 & $279,234,728$ & 9.30 & 10.3 & 34,428 \\
\hline Other workers & 126,380 & 0.75 & 0.6 & 46,561 & $25,754,740$ & 0.86 & 0.9 & 36,733 \\
\hline Tools/Machinery* & $1,097,408$ & 6.48 & 6.0 & 41,079 & $210,741,323$ & 7.02 & 7.5 & 35,658 \\
\hline Vehicular* & $1,015,065$ & 5.99 & 4.2 & 54,240 & $212,027,685$ & 7.06 & 4.3 & 62,828 \\
\hline Work-directed* & $5,391,293$ & 31.82 & 37.2 & 32,366 & $1,099,938,105$ & 36.64 & 39.2 & 35,754 \\
\hline Not otherwise classified* & $1,829,854$ & 10.80 & 12.3 & 33,184 & $349,590,629$ & 11.64 & 14.1 & 31,683 \\
\hline Total & $16,943,846$ & & & & $3,002,327,054$ & & & \\
\hline
\end{tabular}

* Denotes statistical significance for $\%$ of total cost, $\mathrm{p}<0.05$. 


\section{Discussion}

The cost of musculoskeletal injuries in FMP is significant to workers, healthcare professionals and society (Cleve, 2012; Klowden et al., 2010; Leigh et al., 2003; McCann, 1992; Siwek, 2007). In a 1997 cost analysis of US workplace injury, Leigh et al. 2003 concluded that the expense of occupational injuries was unexpectedly high and contrasted sharply with the limited attention received by the public and resources allocated. In a later analysis, Leigh found the societal cost of occupation injuries to be at least as large as that of cancer, and while WC may cover one-quarter of the cost, society is left with remaining burden.(Leigh et al., 2001; Leigh et al., 2003 ) Additionally, up to $20 \%$ of injured workers may not return to work at all, placing additional financial burden on their family and society (Lee et al., 2015). Musculoskeletal injuries are a substantial contributor to this societal burden, constituting roughly $88 \%$ of the total cost of WC claims in not only CA FMP industry (\$16.9 million per year) but across all CA industries ( $\$ 3$ billion per year).

Analyses of national WC databases show a marked difference in compensation for WC claims. Mroz et al 2014 reported an average total cost (medical plus indemnity) of $\$ 6,785$ for 232,399 WC claims in Maryland. Dunning et al reported an even lower average cost of $\$ 5,130$ for 572,508 WC claims in Ohio (Depue, Kagey, \& Heid, 1985; Dunning et al., 2010; Ferguson, Marras, Allread, Knapik, \& Splittstoesser, 2012; Leigh et al., 2001; Leigh et al., 2003; Mroz et al., 2014; Siwek, 2007). Both of these compensation rates pale in comparison to the average cost per claim for CA industries in general $(\$ 38,900)$ and the CA FMP industry $(\$ 38,400)$. A difference of this magnitude is difficult to explain, considering similar time frames for data collection and similar agencies providing the data. Dunning et al did have a slightly different criteria for selecting WC injuries, including only musculoskeletal injuries. Still even the lowest average expenditure in our analysis for any body part, cause or type of injury was still more than twice their mean expenditure. Additionally, other potential reasons for this difference include regional variations such as cost of care, propensity to ignore small injuries and generosity of indemnities (Depue et al., 1985; Dunning et al., 2010; Klowden et al., 2010; Litwak, 1998; Neumark, 2005). However, the more likely source of difference in cost is that our data includes both the cost incurred by the insurer plus an estimated cost for the future for rehabilitation, follow-up visits and future indemnity. It is unclear from the respective methods if the cost data in these other two studies are calculated in the same way (Dunning et al., 2010; Mroz et al., 2014). This finding is critical because it may indicate that the true average cost of workers' compensation claims are up to six times higher than traditionally reported. Regardless, this disparity is a reminder that, despite there being a significant societal cost attributed to WC injuries, there is paucity of data regarding individual industries and a variance in reporting $\mathrm{WC}$ claims in general.

We also found that the cost of orthopaedic injuries per employee per year was $14 \%$ lower in the CA FMP industry than across CA industries. This may be partially explained by the rapid increase in employment in the CA FMP industry without a rise in WC claims over the study period. This may be further explained by the possibility that the new cohort of workers in the CA FMP industry were more likely to utilize private insurance. This would lower the number of public available insurance claims (Dunning et al., 2010; Ferguson et al., 2012; Mroz et al., 2014; Neumark, 2005; Rossol, 2011; Siwek, 2007; SSD \& Design, 2011). However, if this is not the case, this information would be valuable to any insurance companies that would want select a population of workers that are less costly to insure. This may be particularly important information to any new CA health systems that may be planning begin offering their own insurance in the next few years.

The CA FMP industry has a unique profile of cost. Though the most common types, locations and mechanisms of injuries were ranked very similarly between the CA FMP and across CA industries, there was a significant difference in the percent of total cost. The clinical significance of this difference has yet to be determined, but the larger economic and epidemiologic picture is clear: workers, employers, insurance companies and healthcare providers need to be aware of these differences to predict, prevent and treat work place injury. Additionally, the unique injury profile for the CA FMP industry suggests that other industries may also need an individual cost analysis.

The most costly categories of causes of injury were consistent with the most common causes of injury in both groups. Since, presumably, much of a person's time at work is spent doing work-directed activities, it follows that it would be a common cause of injury. Work-directed activities such as repetitive lifting can result in chronic degenerative conditions leading to protracted morbidity and, thus, significant medical costs and indemnity. On the other hand, acute traumatic events such as falls can result in low-level injury also with a protracted recovery and similar costs to the industry. However, the most costly causes of injury per claim were not work-directed or falling, but other, rarer acute incidents such as explosions and vehicle-related injuries. The great potential for severe injury in these cases makes it clear why the average expenditure for these claims is so high. Unfortunately, 
the low frequency of these injuries makes them inefficient targets for prevention. As expected, the overall burden for different types of injury for both groups mirrors the relative frequencies of those types of injuries. Since strains, fractures, sprains and contusions were the most frequent injuries, they would be the largest overall burden on WC claims. These are ideal targets for prevention due to the high frequency and high overall cost.

Our data show that musculoskeletal injury contributes substantially to the medical costs and indemnity. Our findings are invaluable to FMP companies, employees, and the medical community. This study provides an incentive for FMP employers to improve workplace safety and presents relevant data regarding both the absolute and cumulatively most costly types and causes of injury. We hope that by calling attention to the true magnitude of the costs of musculoskeletal injuries that this will move FMP companies to address any deficiencies in workplace safety. Employees should be familiar with the medical costs associated with injuries that may be incompletely covered by WC. Finally, the medical costs are directly relevant to medical professionals treating FMP employees. This study sheds light on the fact that choosing to treat $\mathrm{WC}$ patients can be a very lucrative business, especially for orthopedic surgeons involved in the FMP industry.

\section{Conclusion}

We present the first comprehensive report on the cost of musculoskeletal injury in FMP. Musculoskeletal injuries are clearly a substantial contributor not only to FMP expenditures but also to the burden of health care costs in the US. The cost per claim is substantial and prior analysis shows that approximately one in three workers will make such a claim in their lifetime. This data should provide the FMP industry with not only direction on which areas of workplace safety to improve, but financial incentive to do so. The FMP employer, employee, and medical community alike will benefit from this analysis. Many unanswered questions still remain, and it would be of great interest to both the medical field and to the public to further investigate the costs associated with musculoskeletal injury in film and motion picture and the impact on society.

\section{Limitation}

This study had some unavoidable limitations. Although the WCIRB is the largest and most detailed database for WC claims in general and specifically for the FMP industry, it is only one data source in an industry which is otherwise highly privatized. Furthermore, the WCIRB de-identifies many specifics, which makes it impossible to compare costs to privatize insurance companies or in relation to job description or even gender and age. Finally, since this is the first report of this nature to utilize the WCIRB, the internal validity has yet to be explored. There are potentially substantial issues with collection and quality assurance of these data systems, additionally making inter- and intra-observer reliability difficult to gauge.

\section{Aknowledgements}

Dr. Yazdanshenas is a scholar supported by the Clinical Research Education and Career Development (CRECD), grant 5MD007610, NIH-NIMHD and Accelerating Excellence in Translational Sciences (AXIS) grant NIH-NIMHD \#U54 MD007598.

\section{Conflict of Interest}

The authors declare that there is no conflict of interests regarding the publication of this paper.

\section{References}

Cleve, B. (2012). Film production management. CRC Press.

Depue, R. H., Kagey, B. T., \& Heid, M. F. (1985). A proportional mortality study of the acting profession. Am J Ind Med, 8(1), 57-66. http://dx.doi.org/10.1002/ajim.4700080108

Dunning, K. K., Davis, K. G., Cook, C., Kotowski, S. E., Hamrick, C., Jewell, G., \& Lockey, J. (2010). Costs by industry and diagnosis among musculoskeletal claims in a state workers compensation system: 1999-2004. Am J Ind Med, 53(3), 276-284. http://dx.doi.org/10.1002/ajim.20774

Ferguson, S. A., Marras, W. S., Allread, W. G., Knapik, G. G., \& Splittstoesser, R. E. (2012). Musculoskeletal disorder risk during automotive assembly: Current vs. seated. Appl Ergon, 43(4), 671-678. http://dx.doi.org/10.1016/j.apergo.2011.10.001

Hoe, V. C., Urquhart, D. M., Kelsall, H. L., \& Sim, M. R. (2012). Ergonomic design and training for preventing work-related musculoskeletal disorders of the upper limb and neck in adults. Cochrane Database Syst Rev, 8, CD008570. http://dx.doi.org/10.1002/14651858.CD008570.pub2

Klowden, K., Chatterjee, A., \& Hynek, C. F. (2010). Film Flight: Lost Production and Its Economic Impact on California. Milken Institute, CA center, July. 
Leigh, J. P., McCurdy, S. A., \& Schenker, M. B. (2001). Costs of occupational injuries in agriculture. Public Health Reports, 116(3), 235. http://dx.doi.org/10.1016/S0033-3549(04)50039-0

Leigh, J. P., Yasmeen, S., \& Miller, T. R. (2003). Medical costs of fourteen occupational illnesses in the United States in 1999. Scandinavian Journal of work, environment \& health, 304-313. http://dx.doi.org/10.5271/sjweh.735

Litwak, M. (1998). Contracts for the film \& television industry. Silman-James Press.

Macfarlane, V., Weltz, A., \& Grover, G. (1998). Royal Commission on Workers' Compensation in BC.

McCann, M. (1992). Art Safety Procedures: A Health and Safety Manual for Art Schools and Art Departments. Center for Safety in the Arts.

Mroz, T. M., Carlini, A. R., Archer, K. R., Wegener, S. T., Hoolachan, J. I., Stiers, W., . . Castillo, R. C. (2014). Frequency and cost of claims by injury type from a state workers' compensation fund from 1998 through 2008. Archives of physical medicine and rehabilitation, 95(6), 1048-1054. e1046. http://dx.doi.org/10.1016/j.apmr.2013.11.025

Neumark, D. (2005). The Workers Compensation Crisis in California. California Public Policy, 1, 1-19.

Rossol, M. (2011). The Health and Safety Guide for Film, TV, and Theater. Skyhorse Publishing Inc.

Rules, A. Office of Self-Sufficiency Programs.

Siwek, S. E. (2007). The true cost of sound recording piracy to the US economy. Institute for Policy Innovation.

SSD, W., \& Design, L. K. (2011). Guide to Sources of Statistics-The 2012 Statistical Abstract-US Census Bureau.

\section{Copyrights}

Copyright for this article is retained by the author(s), with first publication rights granted to the journal.

This is an open-access article distributed under the terms and conditions of the Creative Commons Attribution license (http://creativecommons.org/licenses/by/3.0/). 